\title{
China's commercial bank credit business research on challenges and development countermeasures in the age of big data
}

\author{
Wang Yan ${ }^{1, ~ a ~ G a o ~ X i a o h a n ², b ~}$ \\ ('Dalian University of Science And Technology , Dalian 116052)
}

Key words: commercial bank credit business big data countermeasures

\begin{abstract}
The development of modern science and technology takes "the improvement of computing capacity and data mining application and transmission" as its essence, which continuously promotes the development of commercial Banks, and the credit business subconsciously needs to change in the intelligent technical background.Big data technology can build a new credit system perspective for bank credit business, explore the potential value and specific financial status of customers, analyze the potential capacity of customers, reduce the service cost of Banks and reduce the loss of customers. This paper analyzes the current situation of China's commercial Banks' credit business, conducts a SWOT analysis of China's commercial Banks' credit business, analyzes the positive impact of the era of big data on the development of China's commercial Banks' credit business, and puts forward countermeasures for the development of China's commercial Banks' credit business in combination with big data technology.
\end{abstract}

\section{Introduction}

The credit business of traditional commercial Banks plays an important role in China's socialist modernization. As an economic business that most relies on credit rating, the key to the development of credit business lies in how to establish a complete and effective credit rating system. Both the economists and the commercial Banks themselves are striving to establish a better credit rating system in the evolution of the credit business.

At present, the "ant financial service" owned by alibaba group is a good example for the use of big data in the credit business. The new credit model, Peer to Peer Lending, establishes a peer-to-peer Lending model through mobile Internet technology channels and means such as big data and cloud computing.However, this model only on personal consumption loans, small loans, has not been popular in the traditional business of commercial bank credit, after all, the traditional commercial bank has the function of macroeconomic regulation and control is supported by the national economic system, without the development of more sophisticated large data system and establishing perfect credit system, can be put into use directly.

From the perspective of data analysis, this paper analyzes the problems existing in the credit business of China's commercial Banks, conducts SWOT analysis on the credit business of China's commercial Banks based on the current situation, analyzes the opportunities and challenges brought by big data to the credit business, and puts forward development countermeasures for the credit business of China's commercial Banks.

\section{Development status of credit business of China's commercial Banks}

In the process of modern traditional commercial Banks' credit operation, most links must rely on the professional judgment, experience and risk assessment of the credit personnel of commercial Banks. Although there are special risk managers and credit approval committees of commercial Banks to supervise and approve the entire credit process, as shown in FIG. 2-1, the non-performing loan ratio of China's commercial Banks is still on a fast rising trend from 2011 to 2016.

The CBRC released data on major regulatory indicators for the fourth quarter of 2017, which showed that the balance of existing non-performing loans of Chinese commercial Banks was 1.71 trillion yuan, an increase of 1977 billion yuan compared with the non-performing loans at the end of 2016.The non-performing loan ratio of China's commercial Banks in 2016 was 1.74\% (as shown in FIG. 1-1), among which the balance of interest-oriented loans was 3.41 trillion yuan and the ratio of interest-oriented loans was 3.49\%. The loan loss reserve balance of commercial Banks was 3.09 
trillion yuan, an increase of 426.8 billion yuan over the previous year. The provision coverage rate was $181.42 \%$, up $5.02 \%$ from the end of last year. The loan provisioning rate was 3.16 percent, up 0.09 percent from the end of last year.The efforts of inclusive finance have been intensified, with the balance of bank financial institutions' loans to small and micro enterprises and loans related to agriculture reaching 31 trillion yuan, up $15.1 \%$ and $9.6 \%$ respectively from the previous year.Government-subsidized housing project loans increased 42.3 percent year on year, 29.9 percentage points higher than the average growth rate of various loans.(source: China banking regulatory commission).

According to the data analysis, although the loan business in China is in a good state, the non-performing loan ratio of commercial Banks has maintained a basically stable situation throughout the year. But since 2011, the quality of assets of commercial Banks has been deteriorating, mainly due to narrowing net interest margins, rising credit risks and insufficient effective demand supply.

At present, in the competitive state of banking enterprises, the emergence of increasingly rich types of personal consumption and spirit of sharing has brought a great impact on the traditional intermediary function, service mode and operation philosophy of commercial Banks. The new credit model with Internet $\mathrm{P} 2 \mathrm{P}$ as the main one directly impacts the business of traditional bank credit. In contrast, in the past few decades, Chinese Banks have been the golden rice bowl, leading the industry in terms of profitability and a rapidly growing financial system. Therefore, due to the inherent model and the traditional credit system, in this era of rapid development, its shortcomings and pain point slowly emerged.

Because Banks face a large number of loan customers, they must have a complete credit evaluation system. Today, with the booming development of the financial industry, a large amount of accumulated raw data is also an important opportunity for the vigorous rise and development of big data technology. How to analyze and collate these original data so that it can play an important role in post-loan management and future operation is the problem that Banks need to solve at present. P2P platforms connect lenders and borrowers directly through big data, cloud computing and other mobile Internet technologies in a point-to-point manner, eliminating many intermediate costs and improving the efficiency of financial resources and service allocation.

According to the data, in 2009, there were only 9 P2P lending platforms in China, but by the end of December 2015, there were 3,769 P2P lending platforms, 75 times more than in 2011, 273 times more transactions and 333 times more loan balances. The monthly transaction volume of online loan industry has been more than 150 billion yuan since 2017.(source: online loan home).It can be seen that the power of P2P network platform cannot be underestimated.

However, supported by big data platform for P2P can only for individual users and individual and industrial and commercial door, yet this scenario was applied to the enterprise data analysis, part of the reason depends on of enterprises, commercial secrets, unable to realize sharing, more important reason is that the ant gold suit itself strategic focus is scattered by small investment control risk.The enlightenment to commercial Banks lies in establishing their own data system and opening up their own business financial chain.

\section{SWOT analysis based on China's commercial bank credit business}

Strength

1. It plays a role in macro-control.

2.The regulatory system is relatively perfect and people trust it in asset security.

3.Relatively perfect financial infrastructure.

4. Abundant customer resources.
Weakness (Weakness)

1.The financial sector supervision system restricts the comprehensive operation of banking groups

2.High cost, long operating cycle, insufficient network coverage and limited operating time.

3.Asymmetric post-loan management information. 


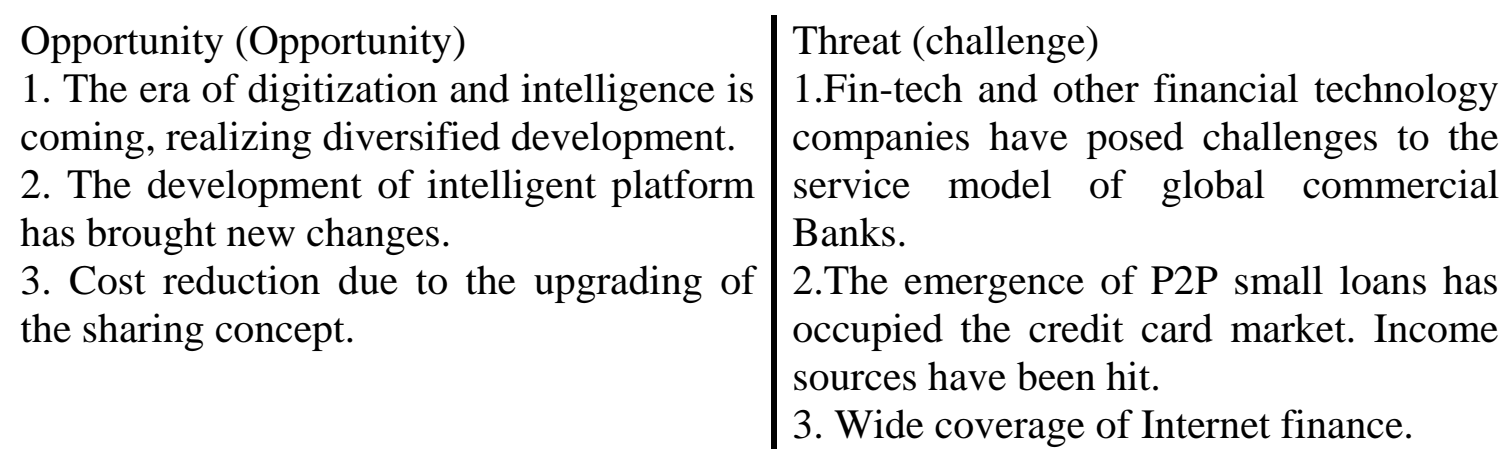

Figure 3-1: SWOT analysis of credit business of commercial Banks

\section{Positive influence of big data era on the development of credit business of China's commercial Banks}

\section{1 "Shared thinking" enters the banking field}

Financial services by the Internet change, private ownership of resources, resources abundance in the bank, can be surplus, non-core implementation making use of resources and resource sharing between government agencies, financial industry, helps to exchange use of idle resources, in terms of the credit business, if the realization of the sharing of a degree of relationship between enterprise operation of other institutions, such as tax institutions, industrial and commercial bureau, etc., to analyze the management of an enterprise in the process of the sense of responsibility and credibility. When applying for loans to enterprises, it can effectively avoid the problem of false and false information.

\subsection{Support the Internet technology of "cloud + intelligent platform + end"}

Make full use of the impact of information technology to create the best customer experience as the ultimate goal to provide customers with free, free and free financial services. First of all, the development of big data can improve the data mining, storage, processing and analysis capacity of Banks, and enhance the ability of data transmission and data screening.It can reduce the data asymmetry before and after loan.

In addition, Internet technology breaks the limitation of time and space and can deliver information timely. It reduces the cost of borrowing, especially the cost of time. The Internet platform is distributed and point-to-point, which is convenient for credit participants to exchange information. Banks can quickly establish preliminary assessments of borrowers through the big data system. The authenticity of the borrower's information can be quickly identified in the audit process. More in the loan after the implementation of the borrower loan use of supervision.

\section{Countermeasures for the development of credit business of China's commercial Banks}

\subsection{Change from traditional "credit product-oriented" to "customer-oriented"}

In the new era of big data, Banks must use big data technology to help customers to allocate real and effective information after customers pass the first round of credit evaluation. At the same time, customers must be tracked throughout. In addition, according to the qualification and demand of customers, we should designate relatively appropriate credit products for them, reduce their repayment pressure, and eliminate their psychological resistance to repayment, so as to reduce the non-performing loan ratio and promote their loyalty to the bank.

\subsection{Based on "real data", change the subjective evaluation system of credit evaluation by manual execution}

What client managers can only determine is that the loan price minus the cost is part of the income. The borrower's risk-weighted income is difficult to estimate in advance, and the risk-weighted pricing is even more difficult to be prepared and judged. Therefore, the risk control efficiency and 
accuracy under symmetric information must be improved with the help of big data technology and artificial intelligence technology.

\subsection{Use big data to budget and estimate the direct impact of the "debt-to-equity swap" of Banks, and promote the effective implementation of the debt-to-equity swap strateg}

Calculations based on big data should be made to estimate the impact of "easing the upward pressure on the rate of underperformance", "bank provisions", interest rates "and" capital adequacy ". As the debt-to-equity swap involves a dense number of participants and involves various financial activities and management activities of different nature, it is possible to prevent the debt-to-equity swap for zombie enterprises, shell enterprises and problem enterprises, otherwise it will increase the burden on the banking enterprises.Therefore, it makes full use of big data to analyze the profitability of enterprises to further determine whether the implementation of the "debt-for-equity" scheme should be carried out for enterprises.

\subsection{Establish a relatively complete new lending system}

(1) platform: realize intelligent risk prevention, control and management through intelligent risk management platform

On the basis of integrating the internal and external data of the banking system and the external data resources such as the Internet, a digital risk quantization model and automatic system analysis capability are established for market risk, liquidity risk, operational risk, collateral, portfolio management, etc., so as to realize automatic risk measurement, self-assessment and reporting.

(2) positioning: assist the strategic development of enterprises through the matching of risks and benefits

Through the reasonable application of data, rich data analysis is used. Besides the traditional risk, the new risk including data privacy risk and credit risk can be prevented. Better overall control. Align risk and reward in a focused search for business advantage. We will use management methods and new tools for risk adjustment performance to preserve and increase capital value.

(3) customer screening: comprehensive risk scanning to determine credit granting access groups

Establish the research and analysis model of each industry, and analyze the data information of each industry. After the comprehensive risk factors are formed, the industry evaluation is combined with the bank's own advantages to select the customer groups that meet the bank's risk preference and access requirements. For existing customers. There must also be a dynamic assessment of whether it is still eligible for a loan.

(4) pre-loan: collect 360 degree information from customers. Create "360-degree" customer portraits

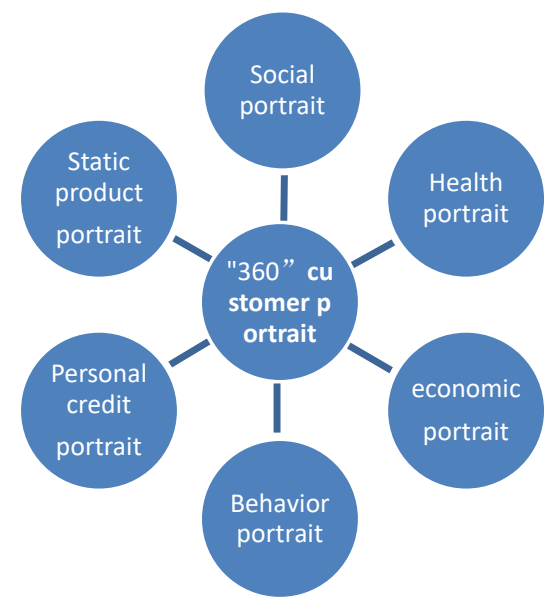

Figure 5-3: "360-degree" full-angle customer portrait information graph

(5) feedback loop: continuous optimization of the closed loop 
Constantly optimize the management system and build a fine policy management system. Through the monitoring of data flow, conduct comprehensive and continuous follow-up intervention, verification and control of credit risk operations, and continuously optimize the feedback. Make each link close to risk policy implementation.

\section{Reference:}

[1] Jane Wallace. Countermeasures and Suggestions for risk management of China's urban commercial Banks' credit operations [J]. National business situation. May 2016

[2] zhu zhongyuan. Analysis on obstacles and solutions for China's commercial Banks to implement green credit business [J]. Theoretical construction. July 2016

[3] ding shaoya. A brief discussion on information asymmetry in the credit business of China's commercial Banks [J]. Journal of henan university of finance and taxation. March 2017

[4] wang zegan. Discussion on China's commercial Banks' credit asset securitization business [J]. Modern business. February 2016

[5] wu tielin. Research on risk control of credit business of commercial Banks [J]. Management and technology of small and medium-sized enterprises. January 2014

[6] yu qiancheng. A brief analysis of commercial bank credit business in the era of big data [J]. Modern business. August 2014

[7] hua yaqin. Opportunities and challenges of credit business of commercial Banks in the era of big data [J]. Times finance. May 2015

[8] zeng liang. Risk management of credit business of commercial Banks [D]. Jiangxi university of finance and economics. May 2017

[9] Thierry Buchs.Johan Mathisen.IMFworkingpaper[J].Authorizedfor distribution by Samuel itam. 2017.05 